\title{
Influence of Diurnal Temperature Range on the Development of Fiber Cells in Flax (Linum usitatissimum)
}

\author{
Guanghui Du ${ }^{1 \dagger}$, Liyan $\mathrm{Wu}^{1,2 \dagger}$, Gang Deng ${ }^{1}$, Yang Yang ${ }^{1}$, Feihu Liu ${ }^{1 *}$ and Gordon Rowland ${ }^{3 *}$ \\ ${ }^{1}$ School of Agriculture, Yunnan University, 2 North Cuihu Lake Road, Kunming 650091, China \\ ${ }^{2}$ Horticultural Institute of Yunnan Academy of Agricultural Science, 2238 Beijing Road, Kunming 650205, China \\ ${ }^{3}$ Department of Plant Science, College of Agriculture and Bioresources, University of Saskatchewan, 51 Campus Drive, \\ Saskatoon, Saskatchewan, S7N5A8, Canada \\ *For correspondence: dmzpynu@126.com; gordon.rowland@usask.ca \\ †Contributed equally to this work
}

\begin{abstract}
Three flax (Linum usitatissimum L.) cultivars ('Ariane', 'Argos' and 'Viking') were used to study the effect of diurnal temperature range (DIF) applied throughout the whole growth stage on the development of fiber cells. Diurnal temperature ranges were set at $5^{\circ} \mathrm{C}, 10^{\circ} \mathrm{C}$ and $15^{\circ} \mathrm{C}$ with the same daily mean temperature and accumulated growing degree days (GDDa). All measured traits showed obvious DIF and varietal differences except the length of fiber bundle (LFB) and the inter-fiber bundle distance (IFBD). Significant interactions of DIF and cultivar were observed to affect the width of fiber bundle (WFB), the size of fiber cell (SFC), the size of fiber cell cavity (SFCC) and the thickness of fiber cell wall (TFCW). Compared with other DIFs, the number of fiber cells per bundle (NFCB) and WFB increased, but IFBD decreased under DIF 5. However, WFB, TFCW and NFCB all decreased under DIF 10. Under DIF 15 condition, both SFC and SFCC increased. For 'Ariane', IFBD was short under DIF 5, but SFC and SFCC were both large under DIF 10. For 'Argos', IFBD was also short under DIF 5. Under DIF 10, WFB, SFC and TFCW were all small, but IFBD was long. For 'Viking', TFCW was small under DIF 10 but large under DIF 15. All these results suggested a definite influence of DIF on the development of fiber cells in flax, and DIF set at $5^{\circ} \mathrm{C}$ benefited the number of fiber cells in a bundle but DIF 15 was optimal for the size of fiber cells. C 2017 Friends Science Publishers
\end{abstract}

Keywords: Flax; DIF; Bast fiber; Fiber cell; Temperature

Abbreviations: DIF, diurnal temperature range; DL, day length; DT, day temperature; GDDa, accumulated growing degree days; IFBD, inter-fiber bundle distance; LFB, length of fiber bundle; NFCB, number of fiber cells per bundle; NL, night length; NT, night temperature; SFC, size of fiber cell; SFCC, size of fiber cell cavity; TFCW, thickness of fiber cell wall; WFB, width of fiber bundle

\section{Introduction}

Flax (Linum usitatissimum L.) is among the oldest crops planted for the dual purpose of seed and fiber (Karg, 2011). It belongs to the genus Linum and family Linaceae. As a minor crop, it is grown in a wide range of countries and climates (Jhala and Hall, 2010). And the utilization of flax for various purposes (industry, bio-pharmaceutical, animal feed and food) is continuing to develop (Jhala and Hall, 2010).

Knowledge of temperature affecting the growth and development of plants is one of the major environmental factors (Ritchie and NeSmith, 1991), which is also very important for flax (Yang et al., 2013). In O'Connor and Gusta's experiments (1994), temperature over a range of 5$15^{\circ} \mathrm{C}$ had no effect on percent seed germination of flax, but temperatures less than $10^{\circ} \mathrm{C}$ could dramatically reduce seedling emergence. Kurt and Bozkurt (2006) found that $20^{\circ} \mathrm{C}$ soil temperature is better for flax seedling emergence than a lower temperature. While, in other study Dybing and Zimmerman (1965) concluded that high temperatures could reduce the number and weight of seeds, and even decrease oil quality of flax during the seed ripening period under controlled environments. And temperature is also customarily assigned a major role in regulation of fatty acid composition of flax oilseeds (Dybing and Zimmerman, 1966).

Diurnal temperature range (DIF) can be described as the difference between day and night temperatures (DT and NT) (Erwin et al., 1989). Negative DIF is a warmer NT than DT, while a cooler NT than DT is termed positive DIF, and a neutral DIF (DIF 0) occurs when the temperatures are the same for day and night (Erwin and Heins, 1995). In some greenhouse crops, DIF influences the plant morphological and agronomic traits such as plant height, internode length,

To cite this paper: Du, G., L. Wu, G. Deng, Y. Yang, F. Liu and G. Rowland, 2017. Influence of diurnal temperature range on the development of fiber cells in flax (Linum usitatissimum). Int. J. Agric. Biol., 19: 595-600 
leaf and shoot orientation, lateral branching length and flower stem elongation (Myster and Moe, 1995; Shimizu, 2007). It was also found to regulate physiological activities of many plant species (Jensen et al., 1996). For flax, Yang et al. (2013) found that diurnal temperature range had a significant effect on the agronomic characters of fiber flax. Diurnal temperature range set at $10^{\circ} \mathrm{C}$ was optimal for biomass, plant height, stem diameter, length and weight of technical stem, and fiber weight of flax, while DIF set at $5^{\circ} \mathrm{C}$ benefited fiber content and seed weight.

The development of phloem fiber cells in flax stem is involved in a series of biological processes which mainly include the elongation of fiber cells (both the coordinated and intrusive growth) (Ageeva et al., 2005) and the thickening of fiber cell wall (Gorshkova et al., 2003). Previous experiments found that the development of fiber cells in flax was significant related to the seasonal temperature pattern and indicated that anti-parabolic seasonal temperature pattern was a much favorable temperature condition for flax growth (Du et al., 2015). But the effects of DIF on the development of fiber cells in flax are still not well understood. So the aim of the present study is to determine how different positive $\operatorname{DIF}\left(5,10\right.$ and $\left.15^{\circ} \mathrm{C}\right)$ influence the fiber cellular traits of flax.

\section{Materials and Methods}

\section{Plant Materials and Culture}

The experiment work was conducted in plant growth chambers in University of Saskatchewan, Canada, using three flax cultivars: 'Ariane', 'Argos' and 'Viking'. 120 flax seeds were planted in four 3-gallon plastic pots $(\mathrm{H} 23 \mathrm{~cm} \times$ D $27 \mathrm{~cm}$ ) for each cultivar in each of three growth chambers replicated thrice. Before sowing, every pot was filled up with Sunshine Mix \# 3 soil (Sun Gro Horticulture Canada Ltd.). 4.5 g plant prod fertilizer (N: P: $\mathrm{K}=15: 30: 15 \%$ ) and $0.15 \mathrm{~g} \mathrm{CuSO}_{4} \cdot 5 \mathrm{H}_{2} \mathrm{O}$ (BDH AnalaR) dissolved in $1.5 \mathrm{~L}$ water were applied to soil of each pot. The position of pots in each chamber were changed every $3 \mathrm{~d}$ in case the light intensity in the chambers was not uniform. Normal managements were used to keep plant growing well. Plants were harvested at the fiber ripening stage (when $90 \%$ bolls of $90 \%$ plants turned brown).

\section{Temperature Treatments}

Different positive DIF levels of $5^{\circ} \mathrm{C}$ (DIF 5), $10^{\circ} \mathrm{C}$ (DIF 10) and $15^{\circ} \mathrm{C}$ (DIF 15) (Table 1) with the same daily mean temperature were set in the experiment under a parabolic seasonal temperature pattern to simulate the situation in northeastern China as the treatments of Yang et al. (2013). The same day length (DL) and night length (NL) were set for each chamber according to the climate data in northeastern China, to emphasize the effect of temperature on flax growth and development (Table 1). The designed accumulated growing degree days (GDDa) was $1200^{\circ} \mathrm{C}$ for all chambers. The growing degree days was calculated by a value based on the integrated product of the number of degrees that air temperature rises above a given threshold value $\left(5^{\circ} \mathrm{C}\right)$ and the number of days in the period during, which this excess was maintained.

\section{Data Collection and Statistical Analysis}

At the fiber ripening stage of flax, 9 representative individual plants were selected randomly from each pot of each cultivar in each chamber. About $2 \mathrm{~cm}$ long sections were cut from the middle part of plant stems and then fixed in FAA $(90 \mathrm{~mL} \mathrm{70 \%}$ ethanol $+5 \mathrm{~mL}$ acetic acid glacial +5 $\mathrm{mL} 40 \%$ formaldehyde) mixed liquid for $24 \mathrm{~h}$. Bare-handed slices were cut from each stem section and examined and photographed with an electron microscope (Zeiss Axioskop 40). Three random slice images were selected from several clear photographs of each sample and used to measure the following parameters (Fig. 1) described by Du et al. (2015). In each photograph, LFB (the maximum fiber bundle value along the stem circumference) and WFB (the maximum fiber bundle value perpendicular to the stem circumference) of three fiber bundles and IFBD between four fiber bundles were measured. One fiber bundle was selected randomly to measure SFC, SFCC and TFCW of all fiber cells (crosssectional area). And NFCB was counted from three fiber bundles. All those parameters were measured by AxioVs40 V 4.7.0.0 software (Copyright C 2006-2008 Carl Zeiss Imaging Solutions $\mathrm{GmbH}$.) except NFCB. All data were statistically analyzed by using SPSS16.0. The results are presented as mean \pm standard error values and variance (ANOVA) was used for testing the differences between different treatments by the SNK test at 0.05 level.

\section{Results}

\section{Effect of DIF and Cultivar on the Fiber Cellular Traits in Flax}

ANOVA analysis of DIF effect on the fiber cellular traits showed that DIFs had a significant influence on the width of fiber bundle (WFB), the inter-fiber bundle distance (IFBD), the size of fiber cell (SFC), the size of fiber cell cavity (SFCC), the thickness of fiber cell wall (TFCW) and the number of fiber cells per bundle (NFCB) (Table 2). Cultivars also had a significant influence on all measured traits except IFBD. Interactions between DIF and cultivar were significant for WFB, SFC, SFCC and TFCW.

\section{Influences of Different DIFs on the Fiber Cellular Traits of Flax}

On average, the effect of three flax cultivars was statistically significant in all cellular traits under three levels of positive 
Effect of Diurnal Temperature Range on the Fiber Cellular Traits of Flax / Int. J. Agric. Biol., Vol. 00, No. 0, 201x

Table 1: Mean daily temperature set at different stages in different diurnal temperature ranges (DIFs)

\begin{tabular}{|c|c|c|c|c|c|c|c|}
\hline \multirow[t]{2}{*}{ Chamber } & \multirow[t]{2}{*}{$\operatorname{DIF}\left({ }^{\circ} \mathrm{C}\right)$} & \multicolumn{5}{|c|}{ Set temperature $\left({ }^{\circ} \mathrm{C}\right)$} & \multirow[b]{2}{*}{$\operatorname{GDDa}^{z}\left({ }^{\circ} \mathrm{C} \cdot \mathrm{d}^{-1}\right)$} \\
\hline & & 1 st $20 \mathrm{~d}$ & 2nd $20 \mathrm{~d}$ & $3 \mathrm{rd} 20 \mathrm{~d}$ & 4th $20 \mathrm{~d}$ & 5 th $20 \mathrm{~d}$ & \\
\hline 1 & 5 & $14(16.5 / 11.5)$ & $18(20.5 / 15.5)$ & $21(23.5 / 18.5)$ & $19(21.5 / 16.5)$ & $13(15.5 / 10.5)^{\mathrm{y}}$ & 1200 \\
\hline 2 & 10 & $14(19 / 9)$ & $18(23 / 13)$ & $21(26 / 16)$ & $19(24 / 14)$ & $13(18 / 8)$ & 1200 \\
\hline 3 & 15 & $14(21.5 / 6.5)$ & $18(25.5 / 10.5)$ & $21(28.5 / 13.5)$ & $19(26.5 / 11.5)$ & $13(20.5 / 5.5)$ & 1200 \\
\hline $\mathrm{DL} / \mathrm{NL}^{\mathrm{x}}(\mathrm{h})$ & & $15.5 / 8.5$ & $15.4 / 8.6$ & $15.3 / 8.7$ & $14.3 / 9.7$ & $13.3 / 10.7$ & \\
\hline
\end{tabular}

${ }^{x}$ DL, day length (hours) for each stage; NL, night length (hours) for each stage

'Numbers within parentheses beside each mean daily temperature are the mean temperatures during the day/ night temperatures

${ }^{z} \mathrm{GDDa}$, accumulated growing degree days. The base temperature of flax is $5^{\circ} \mathrm{C}$

Table 2: ANOVA analysis for the effect of diurnal temperature range (DIF) and cultivar on fiber cellular traits of flax

\begin{tabular}{llll}
\hline Traits & DIF & & Main effects \\
\cline { 3 - 4 } & & Cultivar & DIF $\times$ cultivar \\
\hline LFB & NS & $* *$ & NS \\
WFB & $* * *$ & $* * *$ & NS \\
IFBD & $* * *$ & NS & $*$ \\
SFC & $* * *$ & $* * *$ & $* * *$ \\
SFCC & $* * *$ & $* * *$ & $* *$ \\
TFCW & $*$ & $* * *$ & NS \\
NFCB & $* * *$ & & \\
\hline
\end{tabular}

LFB, length of fiber bundle; WFB, width of fiber bundle; IFBD, inter-fiber bundle distance; SFC, size of fiber cell; SFCC, size of fiber cell cavity; TFCW, thickness of fiber cell wall; NFCB, number of fiber cells per bundle

$*, * *, * * *$ Significant at levels of $0.05,0.01$ and $0.001 ;$ NS, not significant (1-tailed)

Table 3: Fiber cellular traits of flax under different diurnal temperature ranges (DIFs)

\begin{tabular}{|c|c|c|c|c|c|c|c|}
\hline $\operatorname{DIF}\left({ }^{\circ} \mathrm{C}\right)$ & $\mathrm{LFB}(\mu \mathrm{m})$ & $\mathrm{WFB}(\mu \mathrm{m})$ & IFBD $(\mu \mathrm{m})$ & $\mathrm{SFC}\left(\mu \mathrm{m}^{2}\right)$ & $\operatorname{SFCC}\left(\mu \mathrm{m}^{2}\right)$ & $\mathrm{TFCW}(\mu \mathrm{m})$ & NFCB \\
\hline 5 & $168.21 \pm 3.43 a$ & $121.84 \pm 2.80 \mathrm{a}$ & $11.83 \pm 0.49 b$ & $626.55 \pm 14.43 b$ & $81.17 \pm 4.64 b$ & $8.81 \pm 0.13 a$ & $24.32 \pm 0.58 \mathrm{a}$ \\
\hline 10 & $179.19 \pm 4.14 \mathrm{a}$ & $102.84 \pm 2.43 c$ & $15.81 \pm 0.66 \mathrm{a}$ & $579.62 \pm 15.88 b$ & $84.17 \pm 4.43 b$ & $8.16 \pm 0.15 b$ & $22.04 \pm 0.55 b$ \\
\hline 15 & $177.57 \pm 4.33 \mathrm{a}$ & $113.19 \pm 2.81 \mathrm{~b}$ & $16.02 \pm 0.59 \mathrm{a}$ & $718.47 \pm 23.48 \mathrm{a}$ & $120.32 \pm 6.51 \mathrm{a}$ & $8.96 \pm 0.16 \mathrm{a}$ & $22.78 \pm 0.59 \mathrm{ab}$ \\
\hline
\end{tabular}

LFB, length of fiber bundle; WFB, width of fiber bundle; IFBD, inter-fiber bundle distance; SFC, size of fiber cell; SFCC, size of fiber cell cavity; TFCW, thickness of fiber cell wall; NFCB, number of fiber cells per bundle

Different letters show significant difference among the means in each column by SNK test at $\alpha=0.05$

DIF treatments $\left(5^{\circ} \mathrm{C}, 10^{\circ} \mathrm{C}\right.$ and $\left.15^{\circ} \mathrm{C}\right)$ except the length of fiber bundle (LFB) (Table 3). Under DIF 5, IFBD decreased but WFB and NFCB increased compared with under the other DIFs (Table 3). However, WFB, TFCW and NFCB all decreased under DIF 10 than the other DIFs (Table 3). Under DIF 15 condition, SFC and SFCC both increased than under DIF 5 and DIF 10 conditions (Table 3).

\section{Influences of DIF on the Fiber Cellular Traits of Each Flax Cultivar}

The effect of three DIFs on the development of fiber cells in each flax cultivar was deeply considered (Fig. 2). The results showed that the effect of DIF on the fiber cellular traits of each flax cultivar were significant. For 'Ariane', there were statistically significant differences in IFBD, SFC and SFCC. About 'Argos', WFB, IFBD, SFC, TFCW and NFCB showed significant differences under the different DIFs. But for 'Viking', the effect of DIF on the fiber cellular traits was little, but only TFCW had a significant difference under 3 different DIFs.

In short, for 'Ariane', IFBD was shorter under DIF 5 than the other DIFs, but SFC and SFCC were both larger under DIF 10 than DIF 5 and DIF 10 conditions. For 'Argos' grown under DIF 5, IFBD was shorter than under the other
DIFs. Under DIF 10, WFB, SFC and TFCW were smaller and FBD longer than under the other DIFs. For 'Viking', TFCW was smaller under DIF 10 but larger under DIF 15 than DIF 5.

\section{Correlation between Fiber Cellular Parameters of Flax under DIF}

Based on the correlation analysis among all the fiber cellular parameters (Table 4), LFB has a significant positive correlation with all measured traits except NFCB. WFB also has a significant correlation with all measured traits (interfiber bundle distance is significant negative correlation, the others are significant positive correlation) except NFCB. And IFBD has a significant correlation with all measured traits (length of fiber bundle is significant positive correlation, the others are significant negative correlation) except SFCC. SFC has a significant negative correlation with IFBD, but has a significant positive correlation with the other traits. SFCC only has a significant positive correlation with LFB, WFB and SFC. TFCW also has a significant positive correlation with LFB, WFB and SFC, but has a significant negative correlation with IFBD. There were significant positive correlation between NFCB and SFC, and significant negative between NFCB and IFBD. 
Du et al. / Int. J. Agric. Biol., Vol. 19, No. 3, 2017

Table 4: Correlation analysis between seven fiber cellular traits in flax under diurnal temperature range

\begin{tabular}{|c|c|c|c|c|c|c|c|}
\hline Variables & LFB & WFB & IFBD & SFC & SFCC & TFCW & NFCB \\
\hline LFB & 1.000 & & & & & & \\
\hline WFB & $0.285 * * *$ & 1.000 & & & & & \\
\hline IFBD & $0.175 * *$ & $-0.300 * * *$ & 1.000 & & & & \\
\hline $\mathrm{SFC}$ & $0.284 * * *$ & $0.592 * * *$ & $-0.140 *$ & 1.000 & & & \\
\hline SFCC & $0.244 * * *$ & $0.394 * * *$ & -0.090 & $0.663 * * *$ & 1.000 & & \\
\hline TFCW & $0.136^{*}$ & $0.417 * * *$ & $-0.116^{*}$ & $0.728 * * *$ & 0.078 & 1.000 & \\
\hline NFCB & -0.016 & 0.110 & $-0.141 *$ & $0.131^{*}$ & 0.077 & 0.089 & 1.000 \\
\hline
\end{tabular}

LFB, length of fiber bundle; WFB, width of fiber bundle; IFBD, inter-fiber bundle distance; SFC, size of fiber cell; SFCC, size of fiber cell cavity; TFCW, thickness of fiber cell wall; NFCB, number of fiber cells per bundle

$*, * *, * * *$ Significant at levels of $0.05,0.01$ and 0.001 (1-tailed)

\section{Discussion}

Studies of flax and temperature have been reported a lot, but these focused mainly on the effect of different temperatures on seed germination, plant growth, seed yield and oil composition of oilseed flax (Dybing and Zimmerman, 1965; Dybing and Zimmerman, 1966; Green, 1986; O'Connor and Gusta, 1994; Casa et al., 1999; Saeidi and Rowland, 1999; Kurt and Bozkurt, 2006). In fiber flax, Yang et al. (2013) only reported that diurnal temperature range (DIF) had a significant influence on the agronomic traits. However, the mechanism behind DIF effects in flax is still unclear. In our study, the effect of DIF on the fiber cellular traits has been studied using different flax cultivars, and some measured traits showed obvious DIF and varietal differences. This could provide a way for covering mechanisms of the DIF response from the cytological views.

Several studies investigated the influence of positive, neutral and negative DIF on plant growth and development of various greenhouse crop species (Myster and Moe, 1995), and found that positive DIF enhanced stem elongation compared with negative or neutral DIF. From the cellular studies, stems developed under positive DIF have longer cells than under negative DIF, and transverse and longitudinal directions of cell expansions in Arabidopsis thaliana were affected by alternating day and night temperature (Thingnaes et al., 2003). In Lilium longiflorum, Erwin et al. (1994) found that stem parenchyma, stem and leaf epidermal cell length were found to increase as the difference (DIF) between DT and NT increased. But the cell length of Campanula isophylla shoots decreased as the plants were grown under negative DIF (Strøm and Moe, 1997). In this study, without negative or zero DIF, SFC and SFCC (transverse directions) of flax were not found to increase with increasing DIF, but both larger under DIF 15 than the other DIFs. However, whether the fiber cells of flax under DIF 15 also developed longer (longitudinal directions) than DIF 5 and 10 was not clear. Not only the fiber cell, but also the fiber bundle, DIFs also have a significant influence on WFB. And DIF 5 makes the fiber bundle thicker than the other DIFs.

Strøm and Moe (1997) suggested that in C. isophylla the stems under the growth stimulation of positive DIF had a production of both more and longer cells than under

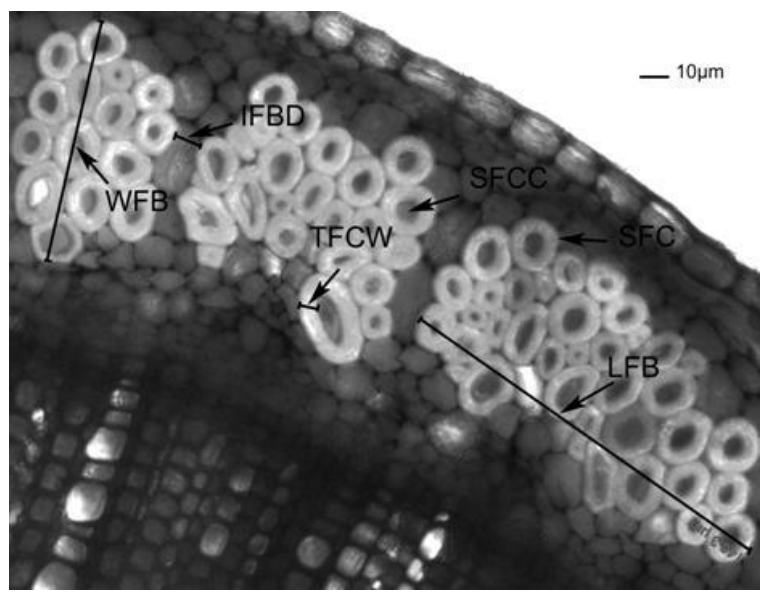

Fig. 1: A sketch cross section of the mid-stem of fiber flax cv. 'Ariane'. LFB, length of fiber bundle; WFB, width of fiber bundle; IFBD, inter-fiber bundle distance; SFC, size of fiber cell; SFCC, size of fiber cell cavity; TFCW, thickness of fiber cell wall

negative DIF. However, in the study by Erwin et al. (1994), it was indicated that the stem elongation of $L$. longiflorum developed at positive DIF was due to only longer but not more cells than at negative DIF. But Thingnaes et al. (2003) also found that the elongation and division of stem cells in A. thaliana were both affected by DIFs. The section samples were chosen only from the middle part of the plant stems in this presented study, which could show an approximate estimate for the entire stem of flax. In this situation, there are more fiber cells in a bundle of flax stem under DIF 5 than other DIFs, which may be a reason why DIF set at $5^{\circ} \mathrm{C}$ benefited fiber content of flax.

Many studies mainly focus on the effect of DIF on the size and number of plant cells (Erwin et al., 1994; Strøm and Moe, 1997; Thingnaes et al., 2003), but there are little reports of the effect of DIF on the other parameters of plant cells. In flax stem, an important process in the development of phloem fiber cells is the thickening of fiber cell wall (Gorshkova et al., 2003). Although the effect of the seasonal temperature pattern on the TFCW of flax was not significantly in the previous report (Du et al., 2015), we found TFCW was thicker under DIF 5 or DIF 15 than DIF 

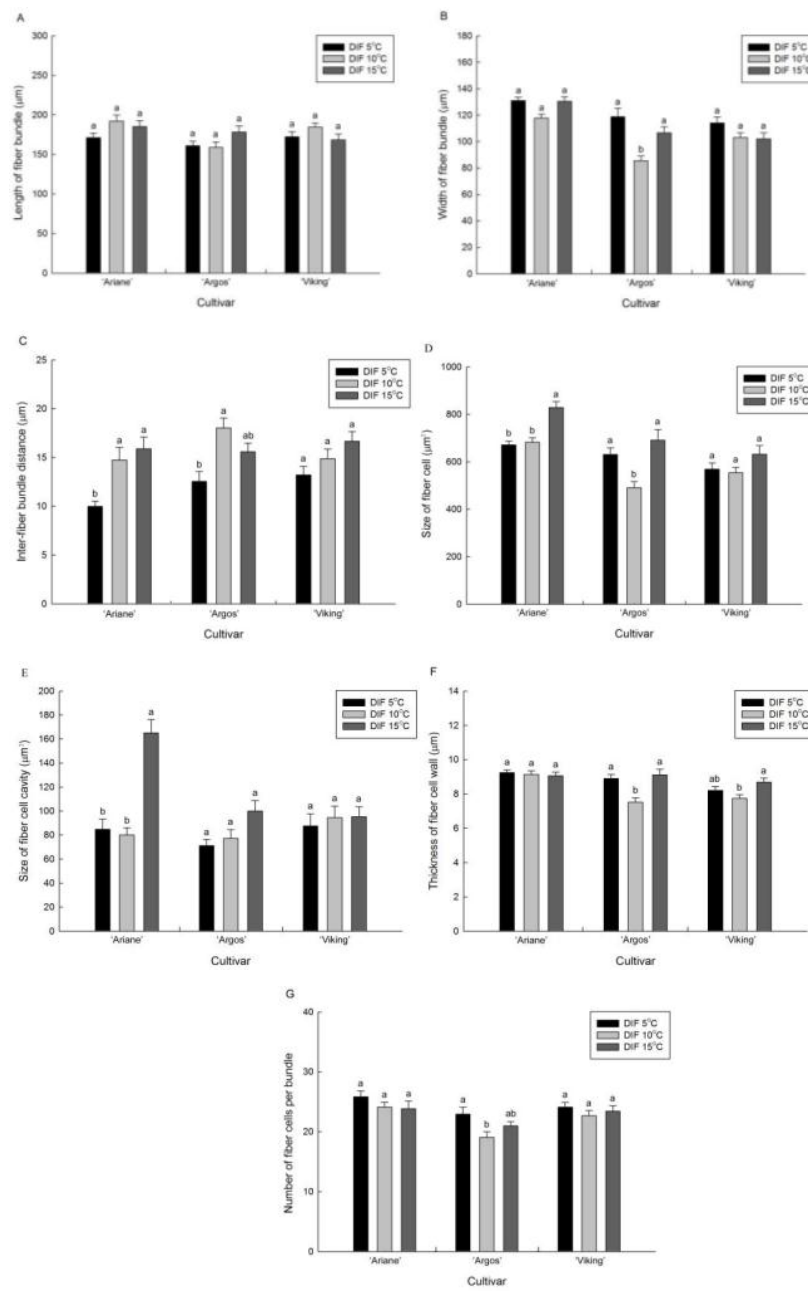

Fig. 2: Measurements of flax fiber cellular traits under diurnal temperature range (DIF). Different letters show significant difference among the means in each column by SNK test at $\alpha=0.05$

10 condition, meaning both big and small difference between day and night temperature prompted the fiber cell wall thickening. Moreover, the fiber cellular parameters of flax under diurnal temperature range were significantly correlated in this study. For example, there were significant positive correlation between $\mathrm{NFCB}$ and $\mathrm{SFC}$, and significant negative correlation between NFCB and IFBD. Thus, it provides some other parameters for verifying the influences of temperature on the development of plant cell. Importantly, we found that some fiber cellular traits (such as WFB and NFCB) were significant correlation with the fiber yield in our previous study (Du et al., 2015). This could provide a method for predicting fiber yield of flax from a cytological angle.

\section{Conclusion}

'Viking', 'Argos' and 'Ariane' are excellent cultivars of flax for fiber production from France, although they have different performance under different temperatures. Cultivars had a significant influence on all measured fiber cellular traits except IFBD. There was an interactions between DIF and cultivar. There were significant differences in many fiber cellular traits for 'Ariane' and 'Argos', but was only TFCW of 'Viking' effect by DIFs. This indicates that 'Viking' is also less responsive to the different DIFs. Thus, 'Viking' may not be a temperature sensitive flax cultivar.

\section{Acknowledgments}

We thank the financial support from China Scholarship Council which made it possible for the experiment to be carried out at College of Agriculture and Bioresources, University of Saskatchewan, Canada.

\section{References}

Ageeva, M.V., B. Petrovska, H. Kieft, V.V. Sal'nikov, A.V. Snegireva, J.E.G. van Dam, W.L.H. van Veenendaal, A.M.C. Emons, T.A. Gorshkova and A.A.M. van Lammeren, 2005. Intrusive growth of flax phloem fibers is of intercalary type. Planta, 222: 565-574

Casa, R., G. Russell, B.L. Cascio and F. Rossini, 1999. Environmental effects on linseed (Linum usitatissimum L.) yield and growth of flax at different stand densities. Eur. J. Agron., 11: 267-278

Du, G.H., F.H. Liu and G. Rowland, 2015. Fiber cell development and fiber yield of flax (Linum usitatissimum L.) affected by the seasonal temperature pattern. Can. J. Plant Sci., 95: 1215-1220

Dybing, C.D. and D.C. Zimmerman, 1965. Temperature effects on flax (Linum usitatissimum L.) growth, seed production, and oil quality in controlled environments. Crop Sci., 5: 184-187

Dybing, C.D. and D.C. Zimmerman, 1966. Fatty acid accumulation in maturing flaxseeds as influenced by environment. Plant Physiol., 41: $1465-1470$

Erwin, J.E., R.D. Heins, and M.G. Karlsson, 1989. Thermomorphogenesis in Lilium longiflorum. Amer. J. Bot., 76: 47-52

Erwin, J.E. and R.D. Heins, 1995. Thermomorphogenic responses in stem and leaf development. Hort. Sci., 30: 940-949

Erwin, J.E., P. Velguth and R. Heins, 1994. Day/night temperature environment affects cell elongation but not division in Lilium longiflorum Thumb. J. Exp. Bot., 45: 1019-1025

Gorshkova, T.A., V.V. Sal'nikova, S.B. Chemikosova, M.V. Ageeva, N.V. Pavlencheva and J.E.G. van Dam, 2003. The snap point: a transition point in Linum usitatissimum bast fiber development. Ind. Crops Prod., 18: 213-221

Green, A.G., 1986. Effect of temperature during seed maturation on the oil composition of low-linolenic genotypes of flax. Crop Sci., 26: 961965

Jensen, E., S. Eilertsen, A. Ernsten, O. Juntilla and R. Moe, 1996 Thermoperiodic control of stem elongation and endogenous gibberellins in Campanula isophylla. J. Plant Growth Regul., 15: 167-171

Jhala, A.J. and L.M. Hall, 2010. Flax (Linum usitatissimum L.): Current uses and future applications. Aust. J. Basic Appl. Sci., 4: 4304- 4312

Karg, S., 2011. New research on the cultural history of the useful plant Linum usitatissimum L. (flax), a resource for food and textiles for 8,000 years. Veget. Hist. Archaeobot., 20: 507-508

Kurt, O. and D. Bozkurt, 2006. Effect of temperature and photoperiod on seedling emergence of flax (Linum usitatissimum L.). J. Agron.., 5: $541-545$

Myster, J. and R. Moe, 1995. Effect of diurnal temperature alternations on plant morphology in some greenhouse crops-a mini review. Sci. Hort., 62: 205-215 
Du et al. / Int. J. Agric. Biol., Vol. 19, No. 3, 2017

O'Connor, B.J. and L.V. Gusta, 1994. Effect of low temperature and seeding depth on the germination and emergence of seven flax (Linum usitatissimum L.) cultivars. Can. J. Plant Sci., 74: 247-253

Ritchie, J.T. and D.S. NeSmith, 1991. Temperature and crop development. In: Modeling Plant and Soil Systems, $2^{\text {nd }}$ edition, pp: 5-29. Hanks, J. and J.T. Ritchie (eds.). American Society of Agronomy Monograph 31. Madison, Wisconsin, USA

Saeidi, G. and G.G. Rowland, 1999. The effect of temperature, seed colour and linolenic acid concentration on germination and seed vigour in flax. Can. J. Plant Sci., 79: 315-319

Shimizu, H., 2007. Effect of day and night temperature alternations on plant morphogenesis. Environ. Cont. Biol., 45: 259-265
Strøm, M. and R. Moe, 1997. DIF affects internode and cell extension growth and cell number in Campanula isophylla shoots. Acta Hort., 435: $17-24$

Thingnaes, E., S. Torre, A. Ernstsen and R. Moe, 2003. Day and night temperature responses in Arabidopsis: effects on gibberellin and auxin content, cell size, morphology and flowering time. Ann. Bot., 92: 601-612

Yang, F., F. Liu and G. Rowland, 2013. Effects of diurnal temperature range and seasonal temperature pattern on the agronomic traits of fibre flax (Linum usitatissimum L.). Can. J. Plant Sci., 93: 1249-1255

(Received 28 September 2016; Accepted 25 March 2017) 